\title{
Teaching Breast Cancer Genetics to Medical Students: Evaluation of a Computer Assister Learning (CAL) Package
}

\author{
Z. Miedzybrodzka ${ }^{1}$, N.M. Hamilton ${ }^{2}$, \\ H. Gregory ${ }^{1}$, B. Milner ${ }^{1}$, I. Frade ${ }^{2}$, \\ T. Sinclair ${ }^{2}$, J. Mollison $^{3}$ and N. Haites ${ }^{1}$ \\ ${ }^{1}$ Department of Medical Genetics, University \\ of Aberdeen, Aberdeen, UK \\ ${ }^{2}$ Department of Public Health, University of \\ Aberdeen, Aberdeen, UK \\ ${ }^{3}$ Medical Faculty CAL Unit, University of \\ Aberdeen, Aberdeen, UK
}

We have developed a CAL package for teaching breast cancer genetics to clinical medical students. Its aim is to explain the principles of genetic predisposition to breast cancer, the association with other cancers, the principles of family history taking and confirmation, risk assessment and possible interventions.

Fourth-year clinical medical students from Aberdeen University were randomised to either conventional teaching or CAL. Forty-eight students attended the evaluation session. Students randomised to conventional teaching participated in a 20 minute mini-lecture (with opportunities for questions) led by one of two clinicians. Those students randomised to CAL completed the CAL package with technical but not academic - support available. Aims and objectives of the mini-lecture were the same as those of the CAL package, both tutors used the same teaching material. At the end of the intervention both groups of students completed a short written assessment comprising:

1. Likert scales asking students to rate how enjoyable, useful, interesting and well explained the subject matter was, and ease of use of the computing software and hardware.

2. MEQ and MCQ questions assessing knowledge and understanding of breast cancer genetics.

There was no significant difference between the CAL and mini-lecture groups in terms of marks or acceptability. Thus CAL is an acceptable and effective method of teaching breast cancer genetics to clinical medical students. It can be run across suitable networks or on stand alone PCs. Although time consuming to develop, the CAL could be used in a variety of settings to increase curriculum flexibility. Methods of motivating students to complete the CAL, and of providing educational support are being explored. If there is sufficient demand the CAL package will be made generally available on CD-ROM. 


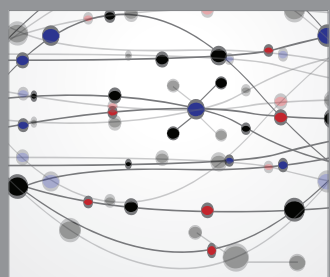

The Scientific World Journal
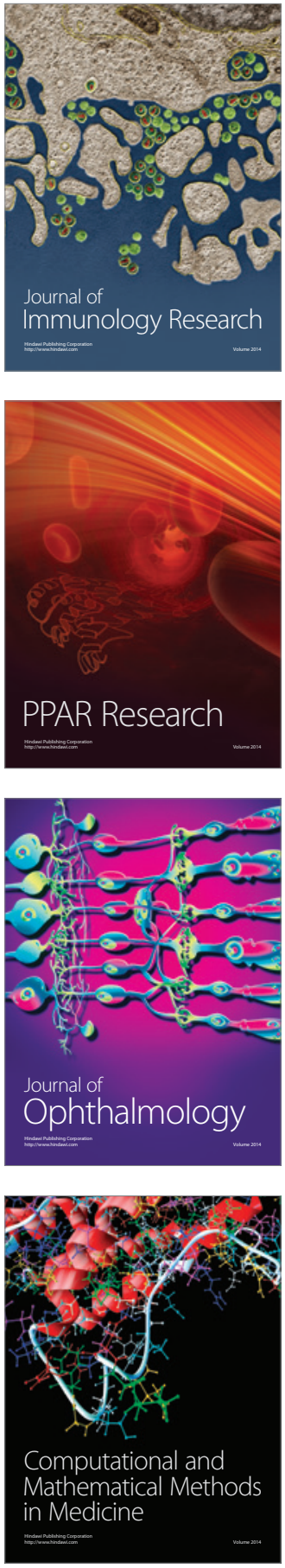

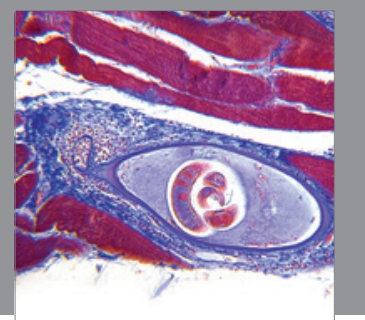

Gastroenterology

Research and Practice
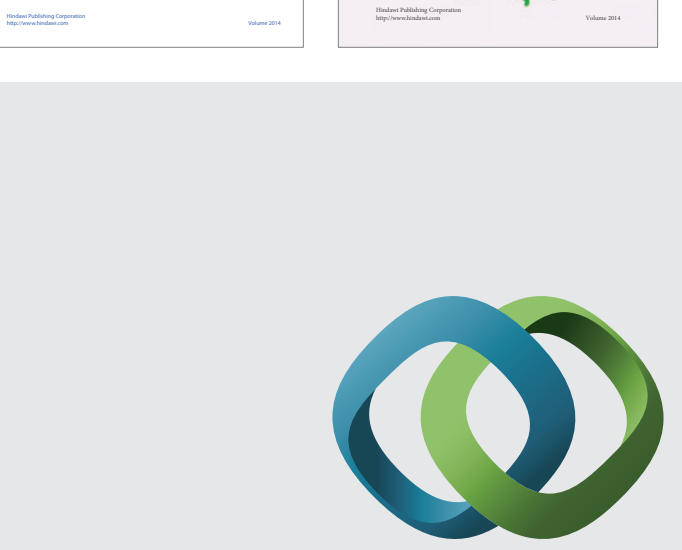

\section{Hindawi}

Submit your manuscripts at

http://www.hindawi.com
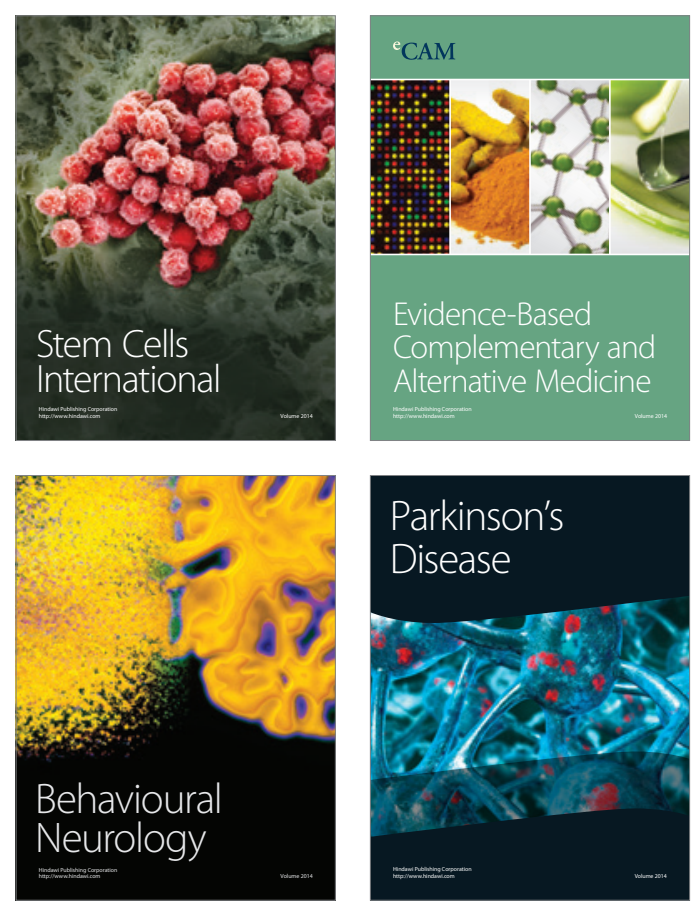

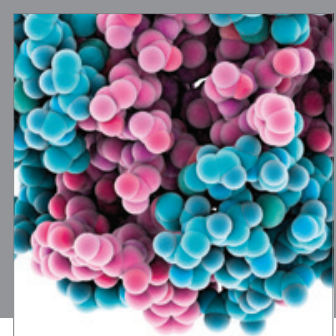

Journal of
Diabetes Research

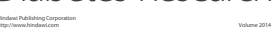

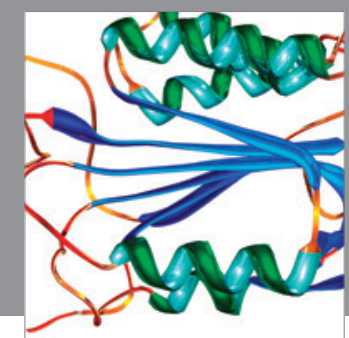

Disease Markers
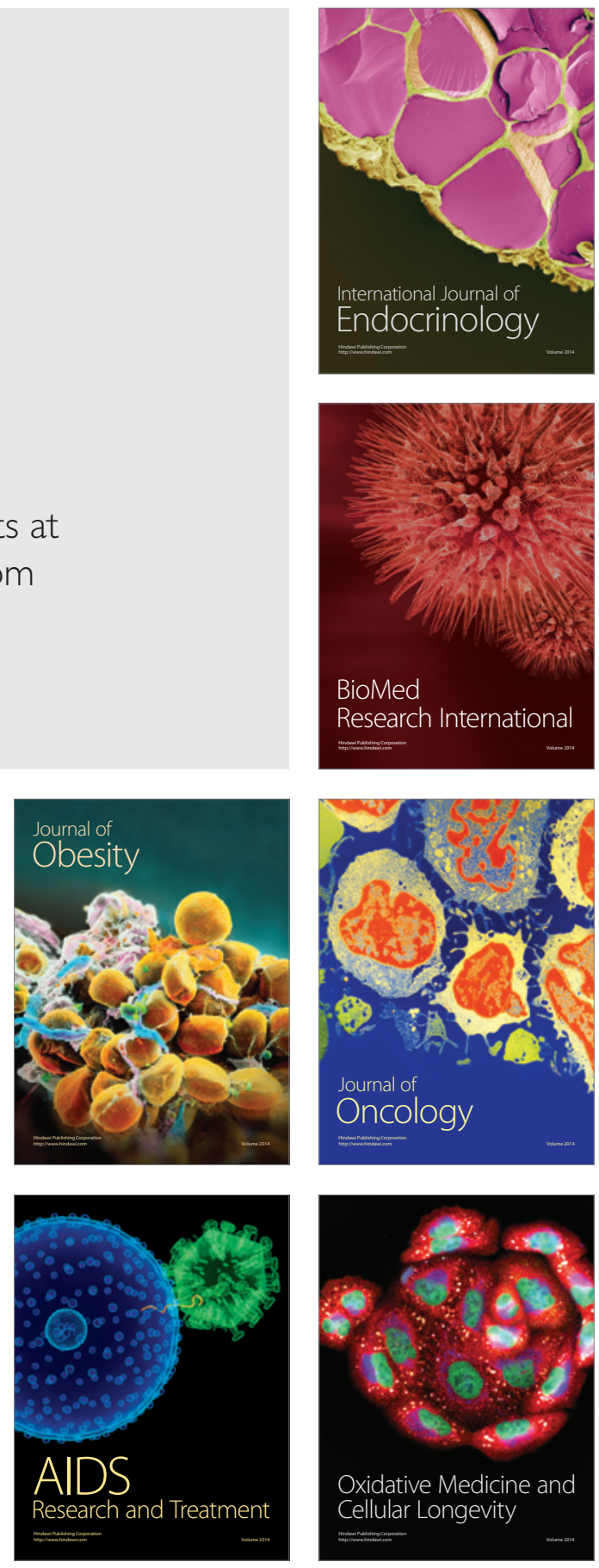